\title{
Is Bacteriolysis In vivo a Friend or a Foe? Relation to Sepsis, Chronic Granulomatous Inflammation and to Oral Disorders: an Overview Hypothesis
}

\author{
Isaac Ginsburg ${ }^{1}$, Erez Koren ${ }^{1 *}$ and Osnat Feuerstein ${ }^{2}$ \\ ${ }^{1}$ Institute for Dental Research, Hadassah Faculty of Dental Medicine, Hebrew University of Jerusalem, Israel \\ ${ }^{2}$ The Department of Prosthodontics, Faculty of Dental Medicine, Hebrew university of Jerusalem, Israel
}

Received: April 16, 2015; Accepted: May 19, 2015; Published: May 29, 2015

*Corresponding author: Erez Koren, Institute for Dental Sciences, Faculty of Dental Medicine, Hebrew University of Jerusalem, Jerusalem, 91120, Israel, Tel: +97-252-397-9931; Fax: +97-226-757073; E-mail: erezkoren@gmail.com

\begin{abstract}
The possible role of antibiotics and of leukocyte-derived cationic peptides as inducers of bacteriolysis in Gram positives and Gram negatives and their involvement in the pathogenesis of chronic granulomatous inflammation is briefly reviewed. It can be speculated that in humans, leukocytes laden with intracellular bacteria and their non-degraded highly-phlogistic cell-walls may be translocated from inflamed gums (periodontal disease) and from infected dental pulps (pulpitis, periapical granulomas) to remote sites such as damaged heart valves (causing endocarditis) and injured joints (causing chronic arthritis). This phenomenon maybe important, clinically and is in line with the old "Focus of infection theory" from the nineteen twenties, which is no longer considered and discussed in the modern literature.
\end{abstract}

Keywords: Bacteriolysis; Antibiotics; Cationic peptides; Translocation; Oral infections; Perpetuating chronic inflammatory processes

\section{Prologue}

Today there is still an ongoing failure to offer an effective treatment for serious sequelae which too often develop following the invasion of the blood stream by microorganism causing severe sepsis and septic shock. Although Gram-positive and negative pathogens are the most common causes of sepsis, fungal involvements in sepsis are rapidly on the rise. It is alarming that according to $\mathrm{CDC}$, the annual incidence of sepsis in the USA affects as many as 750,000 hospitalized patients and the mortality rate is about $40 \%[1,2]$. Although septic shock is strongly associated with microbial infections, bacteria in the blood are found only in about $50 \%$ of cases of severe sepsis and septic shock, and $20 \%$ to $30 \%$ of patients will have no microbial cause identified from any source. However, the possibility should be considered that pathogenic microorganisms may hide in the liver, spleen or in the lung and therefore will not be isolated in blood cultures.

The initial reactions to infection are generalized pro- and anti-inflammatory responses. This usually begins by activation by microorganisms and some of their products of neutrophils, macrophages and monocytes; which is followed by effects on vascular endothelial cells via pathogen recognition receptors. This may lead to host responses and to the mobilization of the complement system, resulting in endothelial cells disruption. It was recently suggested that histones, released from leukocyte nuclei, may be major mediators of death in sepsis $[3,4]$.

Since sepsis may be caused mainly by Gram positives and by Gram negatives, the question was addressed whether we deal with two different clinical manifestations [5]. The authors stated that:

"It has been assumed that the initiation of the systemic inflammatory response with activation of the pro inflammatory cytokine networks and other mediators results in a similar organisms. Systemic immune activation during sepsis may promote the clearance of the microbial pathogen; however, generalized inflammation also contributes to the pathogenesis of septic shock. The balance between these beneficial and deleterious effects may differ between Gram-positive and Gram-negative pathogens pathophysiologic process, regardless of the causative microbic pathogen. Yet, there is increasing experimental evidence that fundamental differences exist in the host response to Gram-positive bacterial pathogens, compared with the host response to Gramnegative."

The main pro inflammatory agonists that may be released into the blood stream following lysis of microorganisms include:

- Cell surface Lipopolysaccharides (LPS) from Gram negatives

- Membrane-associated Lipoteichoic Acid (LTA) from Gram-positives

- Capsular polysaccharides from pneumococci

- Microbial hemolysins and additional membranedamaging agents

- The host may supply : toxic amounts $\mathrm{H}_{2} \mathrm{O}_{2}$, hydroxyl radical, $\mathrm{HOCl}$, Nitric Oxide (NO) and peroxynitrite, Lysosomal acid hydrolases, bactericidal cationic peptides 
(e.g. LL-37), histone, proteinases, phospholipases, coagulation fibrinolysis and complement factors, antibodies, cytotoxic T-cells,TH1 cytokines, chemokines, caspases, leukotrienes, kinins, arachidonic acid, platelet activating factor and eicosanoids.

It is therefore alarming that despite the recognition that post-infectious sequelae may result from a "cross-talk" among a multiplicity of many of these agonists [1,2], to date, all the clinical trials in humans that had tried to alter the course of sepsis by testing only a single antagonist at a time, had failed. It is therefore of great concern that today, even activated protein C, the great hope for sepsis treatment, yielded poor result and the agent was recently removed from clinical use [6]. A strong support for the assumption that the pathophysiology of severe infections and post-infectious sequelae may involve a "cross-talk" among a multiplicity of pro inflammatory agents, but not due to a single agonist, emerged from extensive studies conducted since the early 1970s on the pathophysiology of diseases caused by group A hemolytic streptococci [7] and later on the role of cationic peptides and of certain antibiotics as activators of bacteriolysis [8-15], which may all aggravate the outcome of post-infectious sequelae. It is therefore highly likely that multi-drug strategies, yet to be developed, might better cope with insults caused by cross-talks among a multiplicity of pro inflammatory agents [16].

The present overview stresses the assumption that nonbiodegradable microbial cell-wall components released following bacteriolysis may play a pivotal role in cell and tissue damage observed in chronic inflammatory and granulomatous manifestations.

\section{What is Bacteriolysis?}

\section{Historical notes}

The discovery of microbial cell killing by serum factors dates back to 1883, when Buchner had reported that fresh serum was able to kill certain bacteria but that this property was lost upon heating serum to $56^{\circ} \mathrm{C}$. One year later, Pfeiffer reported the bactericidal dissolution ("Pfeiffer's phenomenon"; bacteriolysis) of cholera vibrio by fresh serum which could be correlated with protection against infection. In 1895 Bordet showed that two factors, a heat-stable (antibodies) and a heat-labile (Alexin) were required for this reaction. Alexin is today known as complement (reviewed By gladsone, et al. 1964) [17]. However, two important events in the field of microbial cell killing and degradation were the discovery in 1928 by Alexander Fleming of the enzyme lysozyme [18] and later on of penicillin [19].

\section{Bacteriolysis: How is it Triggered and How it May Be Involved in Cell and Tissue Damage?}

Bacteriolysis is an event in which the rigid cell-wall of bacteria, comprised of a polymer of N-Acetyl glucosamine $\mathrm{N}$-Acetylmurmaic acid (Peptidoglycan-PPG), is split, allowing the release of intracellular cytoplasmic components, due to the high osmotic pressure of the cell sap [10-12]. Morphologically, two main patterns of microbial cell-destruction can be identified:
- The term 'plasmolysis' is proposed when, either by electron microscopy or by radio-labeling microbial components, a significant degradation of cytoplasmic constituents had occurred but without significantly affecting the structure of the PPG.

- The term 'bacteriolysis' was proposed to indicate a significant breakdown and degradation of the PPG, presumably due to the uncontrolled activation of intracellular autolytic wall enzymes. [11,12,15].

It should, however, be stressed that killing of bacteria either by the immune system (antibodies and complement) or by phagocytes, precedes the phenomenon of bacteriolysis. Therefore, even non-viable bacteria may still contribute to inflammatory responses by supplying pro inflammatory nonbiodegradable cell-wall components. Anecdotally we wonder: "can some life be still left after microbial demise"?

The main biological significance of bacteriolysis in vivo is the presentation of microbial antigens to the immune system. However, the uncontrolled release into the blood stream of microbial capsular polysaccharides, LPS, LTA, PPG, intracellular cytolysins, and histone from neutrophils is probably the main reason for patients' demise. It is conceivable therefore that agent/s, capable of attenuating bacteriolysis in vivo, might be useful to control some of the sequelae of microbial infections especially during antibiotic treatment and in chronic granulomatous episodes (see below).

Lysozyme, the "magic enzyme", secreted by phagocytes, was thought to function to directly cleave bacterial peptidoglycans (PPG), leading to bacteriolysis. However, this was found true mainly for nonpathogenic micrococci used today as a substrate for lysozyme, but is not relevant to other microbial species. It turned out that unlike Micrococci, which possess a "naked" PPG, Staphylococcus aureus and additional pathogenic microorganisms could not be directly lysed by lysozyme because of the presence of 0 -acetyl groups bound to the peptidoglycan $[20,21]$. Furthermore, it was demonstrated that the lytic activity of lysozyme was not associated with its enzymatic activity but due to its high cationic charge [15,20-23]. It was therefore not surprising that spermine, spermidine, chlorhexidine, polymyxin $\mathrm{B}$, the enzymes myeloperoxidase, ribonuclease, phospholipase $\mathrm{A}_{2}$ and elastase, which are all highly cationic, had the ability to lyse Staphylococci by activating their intracellular autolytic wallenzymes, a "Trojan-Horse" phenomenon. Using combinations among lysozyme, $\mathrm{H}_{2} \mathrm{O}_{2}$ and ascorbic acid at $\mathrm{pH} 7.0$ showed that the oxidation of ascorbic acid by hydrogen peroxide gave rise to a very potent antibacterial mechanism, which in presence of lysozyme, induced lysis of Gram negatives [24].

However, when comparing bactericidal and bacteriolytic phenomena, it is important to stress that unlike the short time (minutes) needed to kill bacteria by cationic agents (see review [15], the breakdown of the PPG by cationic peptides - induced autolysins, may take several hours and is optimal at pH5.0, a condition which increases protonation of polycations. While the regulation of the autolytic wall-enzymes in Gram positives 
triggered by polycations and by penicillin (see below) is probably due to Lipoteichoic Acid (LTA) $[12,25,26]$, that in Gram negatives is probably due to phospholipids [15].

\section{Bacteriolysis Induced by Antibiotics}

The extensive use of beta-lactam antibiotics in clinical settings raises the question whether antimicrobials possessing bactericidal or bacteriostatic effects might also act as bacteriolysis-inducing agents (Figure 1). This might be important clinically since microbial lysis may induce the JarischHerxheimer syndrome and there are also evidences from animal models and clinical studies of sepsis that antibiotic-mediated release of biologically-active cell-wall components from Grampositive, Gram-negative or from fungi is associated with a rapid clinical deterioration. Therefore, the antibiotics selected to treat septic patients should be carefully considered [27-29]. One study [30] tested nine antibiotics, representing seven classes, for the amounts of endotoxin released during their action on susceptible strains of Escherichia coli, Klebsiella pneumoniae, Enterobacter cloacae, and Pseudomonas aeruginosa. Aztreonam induced the highest release of endotoxin, whereas other antibiotics, such as imipenem and the quinolones, induced the lowest release of endotoxin. It was also stated that:

"although the quantities of endotoxin released are not easily explained from the established mechanisms of antibiotic action, our findings may have implications for therapy of the acutely ill septic patient in whom release of large quantities of pro inflammatory agents may occur."

\section{What might be the Disadvantages if Bacteriolysis In vivo is Blocked?}

Since cationic agents such as lysozyme, LL37, histone and certain antibiotics can act as bacteriolysis-inducing agents, what might be the side effects if bacteriolysis in vivo is interfered with? It was shown that in vitro, the sulfated compounds heparin, polyanethole sulfonate and Evan's blue markedly depressed lysis of Staphylococci induced by penicillin [31], lysozyme [32] and by complement [33]. Polyanethole sulfonate is routinely added to blood cultures to prevent killing and lysis of Gram-negative by complement thus securing their successful isolation from blood [34]. Lysozyme lysis of Streptococcus sanguis was also shown to be blocked by chitin oligosaccharide [23]. Therefore, these findings suggest that sulfated polysaccharides in infected connective tissues might perhaps modulate bacteriolysis induced by complement, cationic peptides and also by certain antibiotics to allow the persistence of non-biodegradable microbial cellwalls, causing chronic inflammatory episodes [15].

It is accepted that microorganisms may be killed and removed after phagocytosis by PMNs and by macrophages functioning mainly on mucosal surfaces and in tissues. However, it was also shown that during systemic inflammatory responses in severe sepsis, neutrophils accumulated in the liver microcirculation and

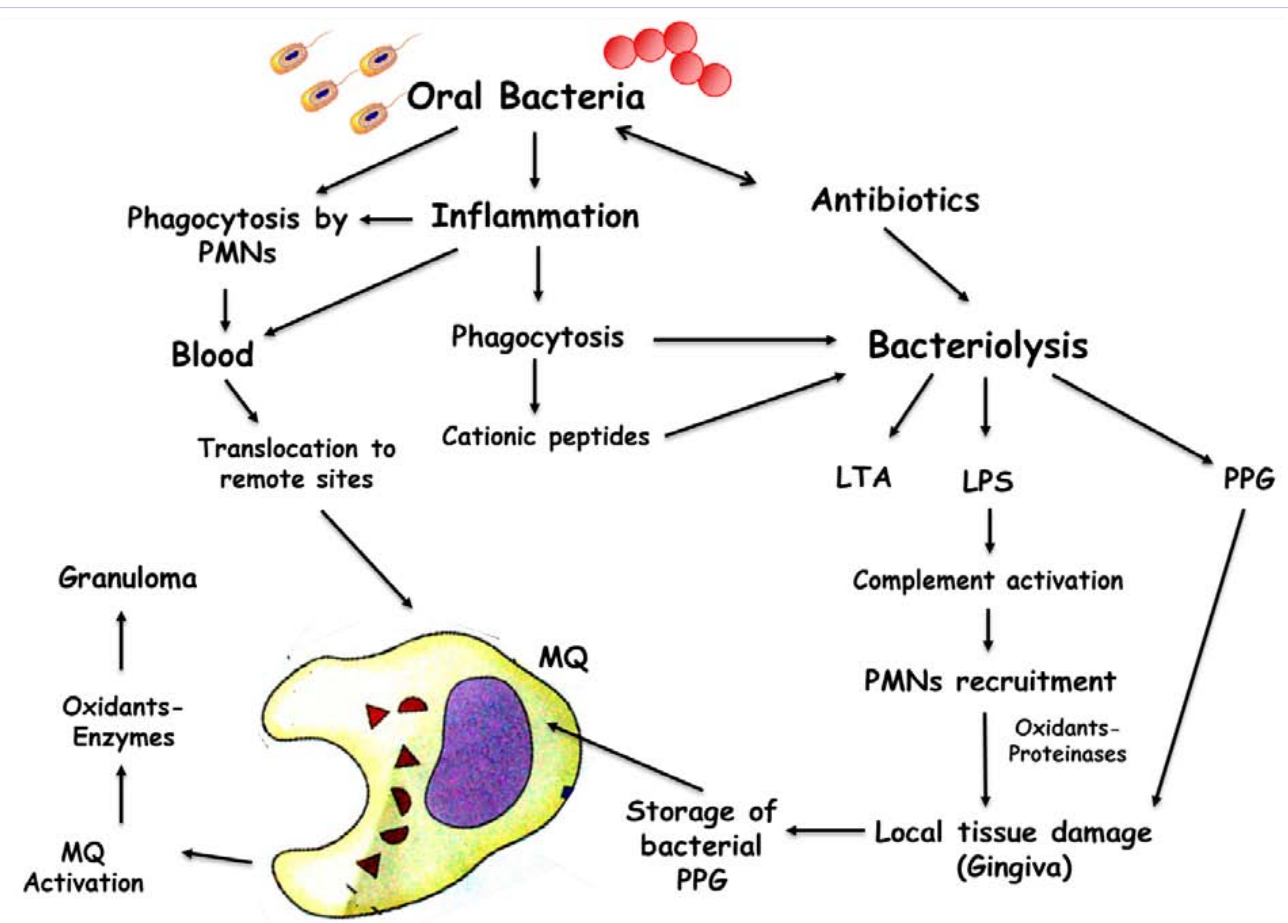

Figure 1: Pathogenesis of inflammation and granulomatous tissue damage caused by translocation of oral microorganisms to injured tissue sites. Oral microorganisms in gingival lesions may undergo bacteriolysis either by cationic peptides or by antibiotics. Phagocytized bacteria and cell walls may reach the blood stream and translocated to remote injured sites like heart valves (endocarditis) or injured joints (arthritis). Products released following bacteriolysis such as PPG (Peptidoglycan), LTA (Lipoteichoic Acid) and LPS (Lipopolysaccharide) can activate complement to recruits neutrophils, which undergo activation to release lysosomal enzymes and oxidants which act in synergy to destroy tissues. Uptake of PPG by macrophages may induce long term granuloma formation. 
Neutrophil Extracellular Nets (NETs) released into the vasculature ensnared bacteria from the bloodstream and prevented their dissemination, this required platelet-neutrophil interactions $[35,36]$. However, it was also suggested that phagocytized bacterial cell-walls might be translocated to remote tissue sites where they can persist for long periods to induce secondary foci of chronic granulomatous inflammation [37,38].It is also possible that in chronic inflammatory conditions macrophages laden with bacterial remnants (PPG) may be retained in situ due to Macrophage Inhibiting Factor (MIF) [39] and to induce granulomas such as seen in mycobacterial and fungal infections (see below). Experimental granuloma formation can also be induced by injecting cell-walls and PPG from different microbial species [15] (Figure 1).

One additional explanation why phagocytes may fail to degrade microbial PPG is the possibility that $\mathrm{H}_{2} \mathrm{O}_{2}$ and proteinases delivered into leukocyte phagosomes following phagocytosis, might destroy microbial autolytic enzymes [40]. This effect could totally be reversed by catalase and by proteinase inhibitors, respectively. It was also shown that myeloperoxidase released by activated neutrophils, prevented the lytic effect of penicillin [41]. Clindamycin retarded the lysis of Staphylococci in macrophages due to the formation of extra thick walls rich in 0-acetyl groups bound to the PPG [42].

\section{Bacteriolysis and Arthritis}

The inability of phagocytes to effectively biodegrade bacterial and fungal cell-wall structures may lead to granulomatous chronic inflammation in infections caused by Mycobacterium tuberculosis, Staphylococcus aureus, Pseudomonas species, Nocardia species, and fungi such as Candida albicans and Aspergillus species. The use of experimental models, mostly in rats, showed a long persistence of microbial cell-walls residing within large macrophages due probably to their inability to degrade the PPG [43-48].Such stimulated macrophages probably release into the surrounding media chemotactic agents, enzymes and cytokines, which can amplify and also further perpetuate the inflammatory responses (Figures 1 and figure 2)

\section{Are Microbial Cell-Walls also involved in the Pathophysiology of Periodontal Disease and in Pulpitis?}

Periodontal disease is an inflammatory affliction of the gums which affects large numbers of the community. It is characterized by a protracted and progressing inflammation of the gingival tissue which, if not treated, might lead to regression of gums, bone loss and eventually to loss of teeth. The main pathogens which are involved in the pathogenesis of periodontal disease are the catalase-negative anaerobes Porphyromonas gingivalis, Fusobacterium nucleatum and Actinobacillus actinomycetemcomitans, and a cross-talk among bacteria, the immune and inflammatory processes are probably the main causes of periodontal disease (Ginsburg, et al. [48], Lamont \& Jenkinson, [49]).

\section{The Pivotal Role of Endotoxin (LPS) in Tissue Damage and in Septic Shock}

As stated by Lamont, et al. in 1998 [49] and by Medianos, et al. in 2005 [50].

"the bacterial components/virulence factors involved in periodontal disease may involve modulating inflammatory responses, which include responses mainly to Lipopolysaccharides (LPS) shed from microbial surfaces by complement, Peptidoglycans
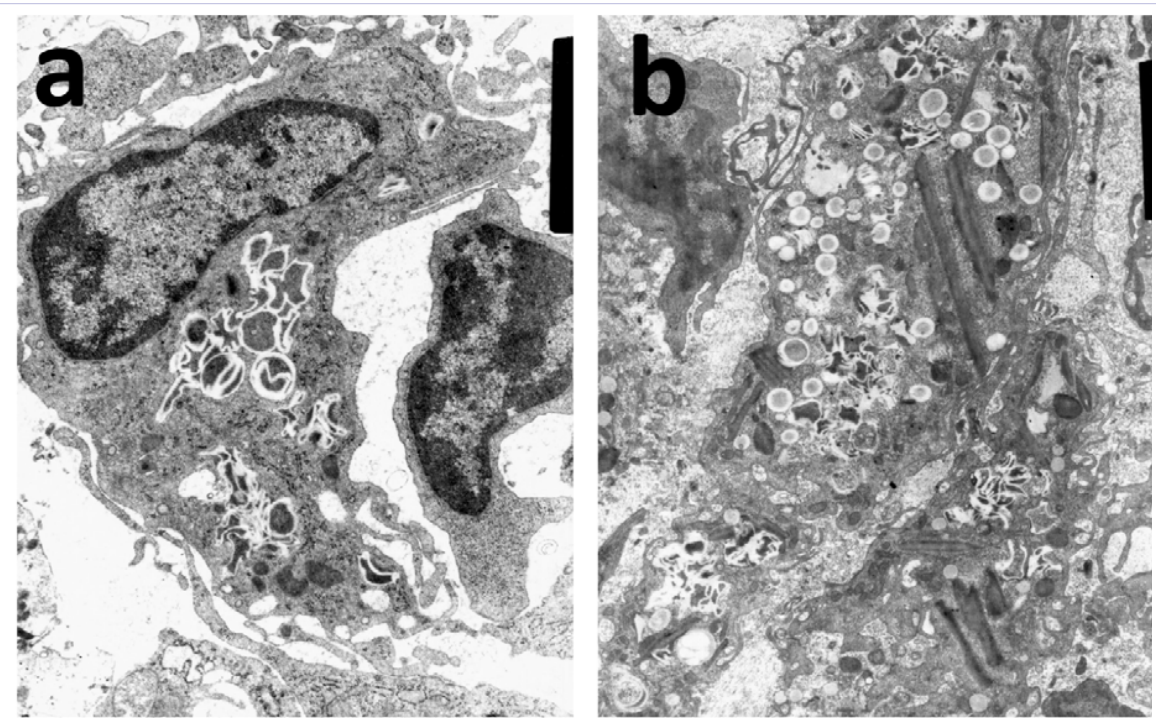

Figure 2: TEM image of a large macrophage in a mouse thigh muscle lesion ten days following injection of Staphylococcus aureus. Note the presence of large number of cell-walls in the cytoplasm, which indicates the inability to degrade peptidoglycan. (b) A cluster of macrophages laden with cell walls obtained from the same specimen. Such macrophages can release a large variety of inflammatory mediators and oxidants. Note that the gray areas within the cell walls are due to the fixative (Magnifications: x10260 for (a) and x5586 for (b)).

We thank Mr. Milu Sadovnic in the preparation of the TEM specimens. 
(PPG), proteases, heat-shock proteins, the highly chemotactic formyl-methionyl peptides, and toxins. Inflammatory responses also involve: Toll-like receptors (tlrs), CD14, nucleotide-binding oligomerization domain proteins (Nod) and G-protein-coupled receptors, including formyl-methionyl peptide receptors and protease-activated receptors. Of the above bacterial and host molecules, evidence from experimental animal studies implicate LPS, fimbriae, proteases, TLRs, and CD14 in periodontal tissue or alveolar bone destruction".

\section{However, as further stated}

"evidence verifying the involvement of any of the above pro inflammatory agents in periodontal tissue destruction in humans, does not exist".

Despite such skepticism, complement-mediated LPS (endotoxin) released from the anaerobes most probably plays a pivotal role in recruiting neutrophils to sites of inflammation where they can induce cell injury in the periodontium and tooth pulp [51]. Experimentally, Lipopolysaccharides (LPS) from Bacteroidesoralis and Veillonella parvula and cell-wall material from Lactobacillus casei were studied for their capacity to induce leukocyte migration into the dental pulp and also in an implanted wound chamber [52]. High molecular weight complexes of bacterial cell-walls may adversely affect pulpal tissue across freshly-exposed dentin. The morphology of human dental plaque has been studied by electron microscopy. In the inner part of the plaque, especially in the region adjacent to the tooth surface, many microorganisms exhibited unusually thick cell-walls, which contained large amounts of intracellular polysaccharide. The magnitude of both phenomena diminished towards the saliva-plaque interface. Sepsis with multipleorgan failure has traditionally focused on lipopolysaccharide of Gram-negative bacteria, the classical endotoxin. However, Gram-positive sepsis now accounts for up to $50 \%$ of all cases, calling for a shift of focus. Peptidoglycan (PPG) which is the major cell-wall component of Gram-positive bacteria can reach the circulation following bacterial breakdown or translocated from the intestine. Administration to animals of PPG induced all the classical features of infectious illness and endotoxemia and may cause systemic inflammation with organ failure [53]. Lipoteichoic Acid (LTA), the regulator of autolysis shed from Gram-positives by antibiotics by lysozyme or also following induction of bacteriolysis by cationic peptides, might also contribute to cell damage [12,54]. Neutrophils treated by LTAanti LTA antibodies, generated large amounts of superoxide and $\mathrm{H}_{2} \mathrm{O}_{2}$ [55]. Lipoteichoic Acid (LTA) released from cariogenic streptococci dwelling adjacent to gingival pockets, might also induce bone resorption [56] and when streptococci were treated with glucose, they also generated large amounts of thiocyaneous acid [57].However, unlike in Gram positives, electron microscopy of the Gram negative E. Coli, treated by complement sufficient serum, revealed only outer-membrane disruption in the form of blebs but the inner microbial membrane and the rigid cell-walls remained intact [58]. Of interest is the ability of cationic lysozyme could detoxify LPS [59].
Taken together, it suggest that similarly to Gram positives, un-degraded PPGs from Gram-negatives might persist for long periods to contribute to the propagation of the inflammatory and destructive processes seen in periodontal disease. The activation of neutrophils in inflamed site might also generate $\mathrm{HOCl}$ capable of injuring tissues. Since similarly to sepsis, periodontal disease is most probably caused by a synergistic cross-talk among a multiplicity of pro inflammatory agents, it stands to reason that multidrug strategies [16], yet to be devised, might be more efficient to suppress tissue damage than the use of single antagonists. Since survival of microbial cell-wall component in tissues may contribute to chronic inflammatory episodes, it is surprising that only a few studies have attempted to identify the possible presence of non-biodegradable microbial cell walls in the inflammatory bed either in the infected peridontium or in dental pulp (Figure 1). Already in 1979, John Schwab, et al. (reviewed in $[11,45,46]$ had proposed to search for bacterial cell-wall components in chronic infected and inflammatory sites. Since microbial Peptidoglycan (PPG) is composed of a polymer of N-acetylglucoseamine - N-Acetylmuramic Acid (NaG-NAM) and since muramic acid is a unique microbial agent, not found in mammals, its identification in the inflammatory bed may indicate the presence of bacterial cell-walls, which can act as potent activators of the immune and inflammatory responses. Also, detecting muramic acid in the dental pulp and in periapical granulomas might be indicative of presence microbial remnants.

\section{Can Catalase-Positive Commensals and Red Blood Cells Secure the Survival of Perio-Pathogens?}

A possible role of the catalase-positive commensals Candida albicans, Staphylococcus aureus, E. Coli and Pseudomonas aeruginosa, and also of red blood cells as protectors against $\mathrm{H}_{2} \mathrm{O}_{2}$ of the catalase-negative perio-pathogens Porphyromonas gingivalis and Fusobacterium nucleatum should be considered. This may be important especially since Chlorhexidine (CHX) is widely used in the oral cavity as a bactericidal agent. In the oral cavity, bactericidal amounts $\mathrm{H}_{2} \mathrm{O}_{2}$ may be produced by cariogenic streptococci grown with glucose [57], and also by mitochondrial respiration and may also be supplied by certain tooth pastes. Therefore, paradoxically perhaps, commensals and catalaserich red blood cells may both protect strict catalase-negative anaerobes, against $\mathrm{H}_{2} \mathrm{O}_{2}$ toxicity (to be published).

Regarding CHX action, recent observations (to be published) suggested that Micrococcus lysodeikticus, the substrate for lysozyme, when coated by CHX, becomes highly-resistant to lysozyme action. Since highly cationic CHX avidly binds to surfaces of many microorganisms, it is possible that treatment with CHX might paradoxically prolong the survival of microbial cell-wall components in tissues.

Since CHX was also found to increase the permeability for $\mathrm{H}_{2} \mathrm{O}_{2}$ of many commensals in the oral cavity and to enhance the decomposition of $\mathrm{H}_{2} \mathrm{O}_{2}$, it might also protect catalase-negative anaerobes against peroxide, leading to their prolonged survival in deep pockets of the gingiva. However, cationic CHX might 
also detoxify LPS [59]. Therefore, CHX has many faces but is still considered as "the gold standard of oral treatment".

\section{Epilogue}

Extensive studies have been performed to explain the possible mechanisms involved in the pathogenesis of septic shock $[1,2,5]$, chronic inflammatory processes such as seen in tuberculosis, arthritis, microbial- and fungal infections, periodontal disease and pulpitis, which many of them are also characterized by longlasting granuloma formation [15,38,43-49]. Since cell and tissue damage in post-infectious sequelae is probably an end-result of "cross-talks" among a multiplicity of pro inflammatory agents and the immune responses of the host [7-10,12], it may suggest that multi-drug strategies, but not single antagonists, could prove more effective protectors against the aftermath of chronic inflammatory episodes [16]. Bacteriolysis is a process where cationic agents such as lysozyme, cationic peptides and certain antibiotics, interfere with intracellular autolytic wall enzymes to induce cell lysis and the release of potent pro-inflammatory entities such as LPS, LTA and PPG [15] (Figure 1). The failure of phagocytes and their hydrolases to effectively dispose of microbial cell-wall components, (peptidoglycans) may be the hallmark of chronic granulomatous tissue responses seen in various inflammatory manifestations [15]. Reduction of tissue damage induced by LPS from Gram-negatives and by polycations from neutrophils may be achieved by sulfated polyanions and agents neutralizing LTA (phospholipids) from Gram positives might mitigate cell damage. The use of antibiotics in sepsis should be selected with care since these may also induce bacteriolysis and the release of highly phlogistic toxic microbial agents [2729]. The role played not only by viable microorganisms but also by remnants of non-biodegradable cell-walls in chronic inflammatory episodes is appealing and looking for muramic acid, a unique microbial agent, in the inflammatory site $[45,46]$, might be helpful to explain the chronicity of inflammation seen in arthritis, periodontal disease and in pulpitis, causing periapical granulomas.

At this point, it should also bring us back to the late eighteen nineties and early nineteen twenties, when the hotly-debated "focus of infection theory" and its relation to oral and systemic manifestations, had been proposed [60-66]. Accordingly, oral microorganisms, involving no less than 500 species, but mainly cariogenic streptococci, staphylococci, strict anaerobes causing periodontal disease, and fungal cells may lodge in injured heart valves (endocarditis), traumatized joints (arthritis) and in additional damaged tissue sites [37,38,62-66]. This phenomenon also led to the proposition that pulling out teeth infested with microbiota might be a proper way to prevent the translocation of bacteria from the oral cavity to remote tissue sites. This further suggests that creating a distant injurious inflammatory site might generate chemotactic agents, which can attract leukocytes laded with non-biodegradable microbial cell wall components and to deposit them in remote tissue sites. However, to prove the presence of microbial cell-wall components in such remote tissue sites necessitates further analysis by electron microscopy, radio labeling of cell-walls, use of mass spectral analysis, bacteriolytic enzymes [67] and the employment of genetic typing procedures. These may further provide more convincing evidences supporting the involvement of oral bacteria in infectious metastatic sites (Figure 1).

Finally, the successful use of Chlorhexidine (CHX) in oral therapy which is due to its substantivity and relatively low toxicity is remarkable $[68,69]$. However, CHX use in the oral cavity might also act as a "double-edged sword" since it can also increase the consumption of $\mathrm{H}_{2} \mathrm{O}_{2}$ by catalase-rich commensals such as Candida albicans, E.coli, Staphylococcus aureus, Pseudomonas species and also by catalase-rich red blood cells endangering the survival of catalase-negative anaerobes, which are highly sensitive to $\mathrm{H}_{2} \mathrm{O}_{2}$ (Ginsburg, et al., Submitted for publication).

Taken together, the dilemma whether cationic peptides and antibiotics-induced bacteriolysis In vivo is friends or a foe (a "double-edged swords"?) Is still not clear [70]. However, the fact that only a very few new publications on bacteriolysis [71-73] had recently been published since we compiled our extensive review in 2002 [15], should not deter further new efforts to analyze and also perhaps "revive" the possible role of "the Focal infection hypothesis" as related to systemic manifestations.

\section{Acknowledgments}

This work was supported by an endowment fund to Isaac Ginsburg from the late Dr. S.M. Robbins of Cleveland, OH, USA. The electron microscopy micrographs were kindly prepared by Mr. Milusadovni.

\section{References}

1. Opal SM. The current understanding of sepsis and research priorities for the future. Virulence. 2014; 5(1): 1-3. doi: 10.4161/viru.26803.

2. Delsesto D, Opal SM. Future perspectives on regulating pro-and antiinflammatory responses in sepsis. Contrib Microbiol. 2011; 17: 13756. doi: 10.1159/000324030.

3. 3. Xu J, Zhang X, Pelayo R, Monestier M, Ammollo CT, Semeraro F, et al. Extracellular histones are major mediators of death in sepsis. Nat Med. 2009; 15(11): 1318-21. doi: 10.1038/nm.2053.

4. Chaput C, Zychlinsky A. Sepsis: the dark side of histones. Nat Med. 2009; 15(11): 1245-6. doi: 10.1038/nm1109-1245.

5. Opal SM, Cohen J. Clinical gram-positive sepsis: does it fundamentally differ from gram-negative bacterial sepsis? Crit Care Med. 1999; 27(8): 1608-16

6. Opal SM, Dellinger RP, Vincent JL, Masur H, Angus DC. The next generation of sepsis clinical trial designs: what is next after the demise of recombinant human activated protein C?* Crit Care Med. 2014; 42(7): 1714-21. doi: 10.1097/CCM.0000000000000325.

7. Ginsburg I, Ward PA, Varani J. Can we learn from the pathogenetic strategies of group A hemolytic streptococci how tissues are injured and organs fail in post-infectious and inflammatory sequelae? FEMS Immunol Med Microbiol. 1999; 25(4): 325-38.

8. Ginsburg I, Kohen R. Cell damage in inflammatory and infectious sites might involve a coordinated "cross-talk" among oxidants, microbial haemolysins and ampiphiles, cationic proteins, phospholipases, fatty acids, proteinases and cytokines (an overview). Free Radic Res. 1995; 22(6): 489-517. 
9. Ginsburg I. Could synergistic interactions among reactive oxygen species, proteinases, membrane-perforating enzymes, hydrolases, microbial hemolysins and cytokines be the main cause of tissue damage in infectious and inflammatory conditions? Med Hypotheses. 1998; 51(4): 337-46.

10.Ginsburg I. Hypothesis: is a failure to prevent bacteriolysis and the synergy among microbial and host-derived pro-inflammatory agonists the main contributory factors to the pathogenesis of postinfectious sequelae? Inflammation. 2001; 25(1): 1-6.

11.Ginsburg I. The biochemistry of bacteriolysis: paradoxes, facts and myths. Microbiol Sci. 1988; 5(5): 137-42.

12. Ginsburg I. Role of lipoteichoic acid in infection and inflammation. Lancet Infect Dis. 2002; 2(3): 171-9.

13. Ginsburg I. Cationic polyelectrolytes from leukocytes might kill bacteria by activating their autolytic systems: enigmatically, the relevance of this phenomenon to post-infectious sequelae is disregarded. Intensive Care Med. 2002; 28: 1188.

14.Ginsburg I. Cationic polyelectrolytes: a new look at their possible roles as opsonins, as stimulators of respiratory burst in leukocytes, in bacteriolysis, and as modulators of immune-complex diseases (a review hypothesis). Inflammation. 1987; 11: 489-515.

15. Ginsburg I. The role of bacteriolysis in the pathophysiology of inflammation, infection and post-infectious sequelae. APMIS. 2002; 110: 753-770.

16. Ginsburg I. Multi-drug strategies are necessary to inhibit the synergistic mechanism causing tissue damage and organ failure in post infectious sequelae. Inflammopharmacology. 1999; 7: 207-217.

17. Gladstone G, Abraham E. Aquired immunity: the serological reactions of bacteria. In: Florey H, editor. General pathology. London: LloydLuke (Medical Books). 1964; 860-879.

18. Fleming A. On a remarkable bacteriolytic element found in tissues and secretions. Proceedings of the Royal Society of London B: Biological Sciences. 1922; 93: 306-317. DOI: 10.1098/rspb.1922.0023.

19. Hugh TB. Howard Florey, Alexander Fleming and the fairy tale of penicillin. Med J Aust. 2002; 177(1): 52-3; author reply 53.

20. Bera A, Herbert S, Jakob A, Vollmer W, Götz F. Why are pathogenic staphylococci so lysozyme resistant? The peptidoglycan 0 -acetyltransferase OatA is the major determinant for lysozyme resistance of Staphylococcus aureus. Mol Microbiol. 2005; 55: 778787.

21. Sahl HG. Bactericidal cationic peptides involved in bacterial antagonism and host defence. Microbiol Sci. 1985; 2: 212-217.

22. Cottagnoud P, Tomasz A. Triggering of pneumococcal autolysis by lysozyme. J Infect Dis. 1993; 167: 684-690.

23. Laible NJ, Germaine GR. Bactericidal activity of human lysozyme, muramidase-inactive lysozyme, and cationic polypeptides against Streptococcus sanguis and Streptococcus faecalis: inhibition by chitin oligosaccharides. Infect Immun. 1985; 48: 720-728.

24. Miller TE. Killing and lysis of gram-negative bacteria through the synergistic effect of hydrogen peroxide, ascorbic acid, and lysozyme. J Bacteriol. 1969; 98: 949-955

25. Shimatani M. [Lipoteichoic acid from Staphylococcus aureus: regulation of autolysis and killing of penicillin. II. Prevention of penicillin-induced lysis by cellular lipoteichoic acid]. Osaka Daigaku Shigaku Zasshi. 1979; 24: 68-73.
26. Ginsburg I. Bactericidal cationic peptides can also function as bacteriolysis-inducing agents mimicking beta-lactam antibiotics?; it is enigmatic why this concept is consistently disregarded. Med Hypotheses. 2004; 62: 367-374.

27. Shenep JL. Antibiotic-induced bacterial cell lysis: a therapeutic dilemma. Eur J Clin Microbiol. 1986; 5: 11-12.

28. Hurley JC. Antibiotic-induced release of endotoxin: a reappraisal. Clin Infect Dis. 1992; 15: 840-854.

29. Periti P, Mazzei T. Antibiotic-induced release of bacterial cell wall components in the pathogenesis of sepsis and septic shock: a review. J Chemother. 1998; 10: 427-448.

30.Eng RH, Smith SM, Fan-Havard P, Ogbara T. Effect of antibiotics on endotoxin release from gram-negative bacteria. Diagn Microbiol Infect Dis. 1993; 16: 185-189.

31. Wecke J, Franz M, Giesbrecht P. Inhibition of the bacteriolytic effect of beta-lactam-antibiotics on Staphylococcus aureus by the polyanionic drugs suramin and Evans Blue. APMIS. 1990; 98: 71-81.

32. Wecke J, Lahav M, Ginsburg I, Kwa E, Giesbrecht P. Inhibition of wall autolysis of staphylococci by sodium polyanethole sulfonate "liquoid". Arch Microbiol. 1986; 144: 110-115.

33. Palarasah Y, Skjoedt MO, Vitved L, Andersen TE, Skjoedt K, Koch C. Sodium polyanethole sulfonate as an inhibitor of activation of complement function in blood culture systems. J Clin Microbiol. 2010; 48: 908-914. doi: 10.1128/JCM.01985-09.

34. Edens RE, Linhardt RJ, Weiler JM. Heparin is not just an anticoagulant anymore: six and one-half decades of studies on the ability of heparin to regulate complement activity. Complement Profiles. 1993; 1: 96120 .

35. McDonald B, Urrutia R, Yipp BG, Jenne CN, Kubes P. Intravascular neutrophil extracellular traps capture bacteria from the bloodstream during sepsis. Cell Host Microbe. 2012; 12: 324-333. doi: 10.1016/j. chom.2012.06.011.

36. Brinkmann V, Reichard U, Goosmann C, Fauler B, Uhlemann Y, Weiss DS, et al. Neutrophil extracellular traps kill bacteria. Science. 2004; 303: 1532-1535.

37. Ginsburg I, Trost R. Localization of group A streptococci and particles of titanium dioxide in arthritic lesions in the rabbit. J Infect Dis. 1971; 123: $292-296$

38. Ginsburg I. Can chronic and self-perpetuating arthritis in the human be caused by arthrotropic undegraded microbial cell wall constituants? A working hypothesis. Rheumatol Rehabil. 1977; 16: 141-149.

39. Nishihira J. Macrophage migration inhibitory factor (MIF): its essential role in the immune system and cell growth. J Interferon Cytokine Res. 2000; 20: 751-762.

40. Ginsburg I. Bacteriolysis is inhibited by hydrogen peroxide and by proteases. Agents Actions. 1989; 28: 238-242.

41. Rakita RM1, Rosen H. Penicillin-binding protein inactivation by human neutrophil myeloperoxidase. J Clin Invest. 1991; 88: 750-754.

42. Wecke J, Johannsen L, Giesbrecht P. Reduction of wall degradability of clindamycin-treated staphylococci within macrophages. Infect Immun. 1990; 58: 197-204.

43. Williams GT, Williams WJ. Granulomatous inflammation-a review. J Clin Pathol. 1983; 36: 723-733.

44. Sartor RB, Herfarth H, Van Tol EAF. Bacterial Cell Wall PolymerInduced Granulomatous Inflammation Methods. 1996; 9: 233-247. 
45. Cromartie WJ, Craddock JG, Schwab JH, Anderle SK, Yang CH. Arthritis in rats after systemic injection of streptococcal cells or cell walls. J Exp Med. 1977; 146: 1585-1602.

46. Clark RL, Cuttino JT Jr, Anderle SK, Cromartie WJ, Schwab JH. Radiologic analysis of arthritis in rats after systemic injection of streptococcal cell walls. Arthritis Rheum. 1979; 22: 25-35.

47. Ginsburg I, Zor U, Floman Y. Experimental models of streptococcal arthritis: Pathogenetic role of streptococcal products and prostaglandins and their modification by anti-inflammatory agents. Experimental Models of Chronic Inflammatory Diseases: Springer. 1977; 6: 256-299.

48. Ginsburg I, Sela MN. The role of leukocytes and their hydrolases in the persistence, degradation, and transport of bacterial constituents in tissues: relation to chronic inflammatory processes in staphylococcal, streptococcal, and mycobacterial infections and in chronic periodontal disease. CRC Crit Rev Microbiol. 1976; 4: 249-322.

49. Lamont RJ, Jenkinson HF. Life below the gum line: pathogenic mechanisms of Porphyromonas gingivalis. Microbiol Mol Biol Rev. 1998; 62: 1244-1263.

50. Madianos PN, Bobetsis YA, Kinane DF. Generation of inflammatory stimuli: how bacteria set up inflammatory responses in the gingiva. J Clin Periodontol. 2005; 32 Suppl 6: 57-71.

51. Daly CG, Seymour GJ, Kieser JB. Bacterial endotoxin: a role in chronic inflammatory periodontal disease? J Oral Pathol. 1980; 9: 1-15.

52. Warfvinge J, Dahlén G, Bergenholtz G. Dental pulp response to bacterial cell wall material. J Dent Res. 1985; 64: 1046-1050.

53. Myhre AE, Aasen AO, Thiemermann C, Wang JE. Peptidoglycan--an endotoxin in its own right? Shock. 2006; 25: 227-235.

54. Sela MN, Lahav M, Ginsburg I. Effect of leukocyte hydrolases on bacteria. IX. The release of lipoteichoic acid from group A streptococci and from Strep. mutans by leukocyte extracts and by lysozyme: relation to tissue damage in inflammatory sites. Inflammation. 1977; 2(2): 151-64.

55. Ginsburg I, Fligiel SE, Ward PA, Varani J. Lipoteichoic acidantilipoteichoic acid complexes induce superoxide generation by human neutrophils. Inflammation. 1988; 12: 525-548.

56. Bab IA, Sela MN, Ginsburg I, Dishon T. Inflammatory lesions and bone resorption induced in the rat periodontium by lipoteichoic acid of Streptococcus mutans. Inflammation. 1979; 3: 345-358.

57. Carlsson J, Iwami Y, Yamada T. Hydrogen peroxide excretion by oral streptococci and effect of lactoperoxidase-thiocyanate-hydrogen peroxide. Infect Immun. 1983; 40: 70-80.

58. O'Hara AM, Moran AP, Würzner R, Orren A. Complement-mediated lipopolysaccharide release and outer membrane damage in Escherichia coli J5: requirement for C9. Immunology. 2001; 102: 365372.

59. Takada K, Ohno N, Yadomae T. Detoxification of lipopolysaccharide
(LPS) by egg white lysozyme. FEMS Immunol Med Microbiol. 1994; 9: $255-263$

60. Pallasch TJ, Wahl MJ. Focal infection: new age or ancient history? Endodontic Topics. 2003; 4: 32-45. doi: 10.1034/j.16011546.2003.00002.x.

61. Gendron R, Grenier D, Maheu-Robert L. The oral cavity as a reservoir of bacterial pathogens for focal infections. Microbes Infect. 2000; 2: 897-906.

62. Ginsburg I, Gallis HA, Cole RM. Group A streptococci: localization in rabbits and guinea pigs following tissue injury. Science. 1969; 166: 1161-1163.

63. Rickles N, Zilberstein Z, Kraus S, Arad G, Kaufstein M, et al. Persistence of group A streptococci labeled with fluorescein isothiocyanate in inflammatory sites in the heart and muscle of mice and rabbits. Proc Soc Exp Biol Med. 1969; 131(2): 525-30.

64. Ginsburg I. The focus of infection theory: a new look at the possible relation to poststreptococcal sequelae. Hum Pathol. 1971; 2: 345-347.

65. Thoden van Velzen SK, Abraham-Inpijn L, Moorer WR. Plaque and systemic disease: a reappraisal of the focal infection concept. J Clin Periodontol. 1984; 11: 209-220.

66. Stein H, Yarom R, Levin S, Dishon T, Ginsburg I, Harris TN. Chronic self-perpetuating arthritis induced in rabbits by a cell-free extract of group A streptococci. Proc Soc Exp Biol Med. 1973; 143: 1106-1112.

67. Salazar 0. Bacteria and yeast cell disruption using lytic enzymes. Methods Mol Biol. 2008; 424: 23-34.

68. Steinberg D, Friedman M, Soskolne A, Sela MN. A new degradable controlled release device for treatment of periodontal disease: in vitro release study. J Periodontol. 1990; 61: 393-398. doi: 10.1007/978-160327-064-9_2.

69. Heasman PA, Heasman L, Stacey F, McCracken GI. Local delivery of chlorhexidine gluconate (PerioChip) in periodontal maintenance patients. J Clin Periodontol. 2001; 28: 90-95.

70. Ginsburg I, Koren E. Are cationic antimicrobial peptides also 'doubleedged swords'? Expert Rev Anti Infect Ther. 2008; 6: 453-462. doi: 10.1586/14787210.6.4.453.

71.Jawale CV, Kim SW, Lee JH. Tightly regulated bacteriolysis for production of empty Salmonella Enteritidis envelope. Vet Microbiol. 2014; 169: 179-187. doi: 10.1016/j.vetmic.2014.01.004.

72. Shinagawa M, Kobayashi D, Goto M, Tanaka M, Kuribayashi K, Yanagihara $\mathrm{N}$, et al. Identification of a bacteriolysis-associated virulence factor against lung epithelial cells in Pseudomonas aeruginosa PAO-1 cell lysate. Microbial Pathogenesis.2014; 75: 35-40. doi: 10.1016/j.micpath.2014.08.002.

73. Sohya S, Kamioka T, Fujita C, Maki T, Ohta Y, Kuroda Y. Biochemical and biophysical characterization of an unexpected bacteriolytic activity of VanX, a member of the vancomycin-resistance vanA gene cluster. J Biol Chem. 2014; 289: 35686-35694. doi: 10.1074/jbc.M114.590265. 